\title{
CONSUMIR PARA SER FELIZ: A CONDUÇÃO DA INFÂNCIA PELA LÓGICA DO CONSUMO
}

\author{
Daniela Pederiva Pensin ${ }^{1}$, Patrícia Gräff²
}

\begin{abstract}
Resumo: Neste texto abordamos a condução das condutas infantis pela mídia televisiva. Para isso, percebemos nos especiais de Natal da Turma da Mônica, transmitidos em canal aberto de televisão, na véspera de Natal, em 2002 e entre os anos de 2009 e 2012, uma interessante materialidade para estudo, pela abrangência de um programa formado por personagens reconhecidos pelas crianças e veiculado em horário matinal. Olhamos para esse conjunto de vídeos a partir de um referencial pós-estruturalista, pautadas, nos estudos de Michel Foucault sobre biopolitica. Interessa-nos entender a condução de um tipo de conduta infantil, pela ênfase no consumo de presentes natalinos como recompensa por (supostas) boas ações empreendidas ao longo do ano. A conformação de um tipo de infância consumidora parece-nos constituir a centralidade dos vídeos, conduzindo as infantes a partir de uma lógica mercadológica.
\end{abstract}

Palavras-chave: Condução da conduta. Infância. Consumo. Felicidade.

\section{CONSUME TO BE HAPPY: THE CHILDHOOD CONDUCTION BYTHE LOGIC OF CONSUMPTION}

\begin{abstract}
In this paper we bring a discussion of the conduct of children's conduction by the television media. For this, we realize in the Christmas specials of the Turma da Mônica, transmitted in open television channel, on Christmas Eve, in 2002 and between the years 2009 and 2012, an interesting materiality to study, by the suggestive scope of a program made up of recognized personages by children and transmitted in morning schedule. We look at this set of videos from a post-structuralist framework, guided, above all, in the studies of Michel Foucault on biopolitics. We are interested in understanding the conduct of a type of child conduct, the emphasis on the consumption of Christmas gifts as rewards for (supposed) good actions undertaken throughout the year. The conformation of a type consuming childhood seems to constitute the centrality of videos, conducting infants from a market logic.
\end{abstract}

Keywords: Conduction of conduct. Childhood. Consumption. Happiness.

1 Pedagoga. Mestre em Educação pelo Instituto Latinoamericano y Caribeño - Cuba. Doutoranda em educação pela Universidade do Vale do Rio dos Sinos - Unisinos. Professora e assessora pedagógica na Universidade do Oeste de Santa Catarina - Unoesc. Bolsista Capes/Proex. E-mail: daniela.pensin@unoesc.edu.br

2 Educadora Especial. Mestre em Educação nas Ciências pela Universidade Regional do Noroeste do Estado do Rio Grande do Sul. Doutoranda em educação pela Universidade do Vale do Rio dos Sinos - Unisinos. Professora na Faisa Faculdades. Bolsista Capes/Proex. E-mail: patigraff@yahoo.com.br 
Tão logo aprendem a ler, ou talvez bem antes, 'a dependência das compras' se estabelece nas crianças (BAUMAN, 2008, p. 73).

As crianças são introduzidas, desde cedo, na lógica do consumo, como afirma Bauman (2008), o que nos permite deduzir que, nas sociedades contemporâneas, essa lógica se produz como um imperativo. Por imperativo referimos a uma necessidade imperiosa que passa a orientar um aspecto específico da vida da população. Entendemos que o consumo se produz a partir da articulação de cada indivíduo como engrenagem na composição do jogo econômico (LOPES, 2009). Um conjunto de estratégias passa a ser empreendido para que todos constituam em si condições mínimas para manterse no jogo, seja na posição de consumidores, seja na posição de competidores. Para azeitar as engrenagens e permitir o funcionamento ininterrupto desse jogo, tornase necessário instrumentalizar, cada vez mais cedo, os jogadores para que produzam em si as dobradiças adequadas, os encaixes exatos para esse modo de vida. Em se tratando de "jogadores infantis", a mídia televisiva desempenha papel fundamental na sua instrumentalização, considerando-se que as crianças passam em frente à televisão tempo superior ao do turno escolar, por exemplo.

Nesse registro, percebemos que as crianças são incitadas, desde muito cedo, a desejar produtos que, em muitos casos, tornam-se recompensas pela prática do que se convencionou chamar de boa açã $o^{3}$. Brinquedos se transformam em instrumentos de barganha na obtenção do que se deseja, fazendo com que os infantes aprendam precocemente as regras desse jogo chamado mercado. Interessa-nos, ao longo deste texto, analisar como se produzem, desde a infância, práticas que atrelam, ao consumo, certo tipo de felicidade e inserem as crianças em uma lógica mercadológica.

Propomo-nos a problematizar a constituição de um tipo de infância orientada para o consumo, tomando como superfície de análise os especiais de Natal da Turma da Mônica, veiculados em canal aberto de televisão, na véspera de Natal, em 2002 e entre os anos de 2009 e 2012. A abrangência de um desenho animado transmitido em todo o território brasileiro, pela televisão aberta, em horário matinal, parece-nos estratégica para determinar sua escolha como material de análise. Esta superfície nos permite perceber a operação de práticas que instigam o desejo e o consumo de mercadorias, na forma de presentes natalinos, como meio para garantir a felicidade.

Para mostrar as práticas que nos permitem enxergar a produção de uma infância consumidora organizamos este texto a partir da problematização de dois eixos

3 Uma boa ação, no entendimento deste texto, está compreendida no contexto de práticas que sejam orientadas pela moral. Esta aproximação à moral (importante que se diga que a moral é de um tempo e de um espaço) traz consigo uma noção de dualidade. Trata-se do certo ou invés do errado, da prática do bem em oposição ao mal. No caso específico deste texto, a moral a que nos referimos possui articulação com a moral cristã e está atrelada à disciplina e ao autocontrole em relação aos comportamentos considerados adequados, especialmente sob o ponto de vista dos adultos. A boa ação é aquela realizada por quem tem inclinação ao bem, a fazer o que é "certo". 
principais que se articulam na sustentação do argumento central. Deste modo, discutimos, em um primeiro momento, a composição de um cenário sobre o qual nos parece emoldurar-se a lógica de consumo, pelo tensionamento do aporte teórico que baliza nossa análise. Em um segundo momento, apresentamos as ênfases discursivas que nos possibilitam entender o consumo de mercadorias como sinônimo de felicidade. Propomo-nos a discutir, ainda, as estratégias de controle que vinculam a prática de boas ações a possibilidades de recompensa ou punição, atreladas ao presente (no sentido material). Antes de adentrar a primeira seção, importa destacar que, para empreender o exercício pretendido ao longo deste texto, utilizamo-nos de um aporte teórico de inspiração Foucaultiana, que nos permite exercer a suspeita e colocar em suspenso algumas verdades produzidas a partir de invenções contingentes.

\section{Balizas teóricas: de onde partimos}

Para instituir as balizas que orientam nosso olhar para o tema proposto, começamos por definir o que entendemos por infância para o recorte proposto neste texto. Dentre as múltiplas possibilidades de conceituar essa fase da vida, aportamos na definição que nos oferece Pagni (2010, p. 66), ao descrevê-la como "um estado no qual algo vai tomando forma”. Parece-nos adequado pensar a infância como primeira etapa de conformação da conduta. Hannah Arendt (1979) assinala a infância como fase em que o indivíduo começa a tomar contato com um mundo que já existia antes da sua chegada. Nesse processo de tomar contato e adaptar-se a um tipo de sociedade que antecede o indivíduo, produzem-se práticas que nele imprimem características que lhe permitam inserir-se e permanecer na sociedade.

Nesse registro, a noção de biopolítica, elaborada por Foucault (2010), parece produtiva para articular algumas engrenagens que permitam o controle da infância e a definição de algumas ênfases na condução das condutas infantis. O filósofo francês entende biopolítica como uma tecnologia de poder que se constitui no final do século XVIII e provoca um deslocamento de ênfases do homem-corpo para o homem-espécie (FOUCAULT, 2010), pelo esmaecimento do eixo disciplinar e pela ênfase no eixo do controle, que permite o exercício do poder sobre o conjunto de indivíduos que forma uma população, neste caso, a população infantil. Foucault (2010, p. 204) diz que, "depois de uma primeira tomada de poder sobre o corpo que se fez consoante o modo da individualização, temos uma segunda tomada de poder que, por sua vez, não é individualizante mas que é massificante". Ao operar sobre as massas, essa nova tecnologia de poder exerce controle sobre a vida da população e passa a ser denominada como biopolitica, pelo filósofo.

Com Foucault (2010) entendemos que não há o fim da ênfase na disciplina e o início da ênfase no controle, mas que ambas se entrecruzam para produzir indivíduos adequados às demandas de cada sociedade e de cada época. Distintas práticas permitem o funcionamento dessas engrenagens e aparecem explícita ou sutilmente no cotidiano 
da população, operadas por cada um de nós. Com isso queremos aproximar tais noções do mundo da vida, daquilo que empreendemos todos os dias, sem mesmo nos dar conta.

Parece-nos que, na contemporaneidade, as mídias, sobretudo a mídia televisiva, têm contribuído para a disseminação de um tipo de conduta infantil que opera a partir da lógica do consumo e potencializa a produção, nos indivíduos, de um conjunto de características adequadas ao modo de vida contemporâneo. Interessa-nos problematizar a constituição de uma infância consumidora que se produz no cruzamento entre o consumo de objetos e uma (suposta) sensação de bem-estar e felicidade, atribuída ao brinquedo. Entendemos que, ao vincular uma possibilidade de ser feliz ao recebimento de presentes natalinos, os programas escolhidos para compor a superfície analítica, constituem estratégias biopolíticas de poder sobre a infância e produzem crianças consumidoras, consoantes com um tipo de sociedade de consumo.

Richard Sennett (2012) tensiona a produção de uma lógica de consumo na formação de um tipo de desigualdade, visualizada nas sociedades Contemporâneas. De acordo com dados apontados por ele, "nos Estados Unidos, o poder aquisitivo das crianças entre quatro e doze anos aumentou de pouco mais de 6 bilhões de dólares em 1989 para mais de 23 bilhões em 1997 e 30 bilhões em 2002" (Ibidem, p. 173), mostrando o enredamento das crianças nas redes de consumo. No Brasil, embora não tenhamos encontrado dados estatísticos sobre o consumo infantil, percebemos que esse campo também preocupa o Estado. De acordo com a cartilha Consumismo infantil: na contramão da sustentabilidade, elaborada pelo Ministério do Meio Ambiente, as crianças passam, em média, 5 horas diárias em frente à televisão, aspecto apontado como um dos responsáveis pelo consumismo e pelo aumento nas taxas de obesidade infantil. Nessa mesma direção, o Instituto Brasileiro de Opinião Pública e Estatística (IBOPE), em pesquisa realizada em $2013^{4}$, aponta dados que demonstram o aumento do tempo de exposição diário médio dedicado à televisão. O histórico dos dados mostra que, desde 2008, o consumo individual de televisão aumentou em todas as segmentações e, de modo mais efetivo, entre crianças de 4 a 11 anos.

Ao relacionar consumo infantil como exposição à televisão, a referida cartilha nos direciona para a materialidade analisada ao longo desse texto. Olhamos para os programas televisivos denominados Especiais de Natal da Turma da Mônica para entender um tipo de foco no consumo, diferente das propagandas que têm na comercialização de determinados produtos seu objetivo principal. Entendemos que na relação entre brinquedo e felicidade disseminada em todas as edições analisadas do programa, concentra-se uma ênfase no consumo de brinquedos, criando uma necessidade mercadológica que atribui significado para o evento natalino. Não temos, com isso, o objetivo de empreender uma análise de cunho religioso. Queremos compreender um tipo de infância consumidora produzido pelo programa. Para isso, ao longo da

4 Disponível em: <http://www.ibopeinteligencia.com/noticias-e-pesquisas/brasileiros-passam-maistempo-em-frente-a-tv>. Acesso em 22/05/2016. 
próxima seção, olhamos para os discursos dos personagens em cada um dos especiais transmitidos em canal aberto de televisão, no ano de 2002 e durante os anos de 2009 e 2012, ressaltando que tais programas se destinam ao público infantil para tratar da temática natalina.

\title{
Os presentes natalinos na produção de uma infância consumidora
}

\author{
Existe hoje um gigantesco mercado voltado para os consumidores infantis, \\ um mercado de brinquedos descolados, roupas que-não-podem-deixar-de- \\ ser-compradas, jogos, e gadgets eletrônicos. [...] Como em qualquer esfera do \\ consumo, esse gigantesco mercado quer convencer os compradores juvenis de que \\ precisam daquilo que ainda não têm (SENNETT, 2012, p. 173).
}

Relações de produção e consumo têm se estabelecido cotidianamente na vida dos indivíduos na Contemporaneidade. Suspeitamos que esta lógica mercadológica produza efeitos sobre as relações entre adultos e crianças e das crianças entre si e consigo mesmas. Percebemos a conformação de um tipo de condução das condutas operado a partir das influências da mídia e da cultura do consumo. Vivemos uma espécie de invasão da mídia: televisão, internet, rádio, entre outras, adentram massivamente nosso cotidiano e o cotidiano das crianças, que, em sua maioria, nascem imersas num universo midiático. Nesse contexto, proliferam canais direcionados exclusivamente ao público infantil. A mídia, e de modo mais específico a televisão, acaba por "assumir um papel significativo na construção de valores culturais. A cultura do consumo molda o campo social, construindo, desde muito cedo, a experiência da criança e do adolescente que vai se consolidando em atitudes centradas no consumo" (CAMPOS; SOUZA, 2003, p. 14).

A infância, ao assumir um lugar na lógica do consumo diminui sua diferenciação em relação à juventude e à adultez, o que transforma as formas como as crianças se inserem no mundo. A conduta infantil passa a ser conduzida a partir de outras ênfases, dentre elas a de que, pelo consumo, é possível chegar à felicidade ou, o que pode trazer ainda mais impactos sobre a conduta infantil, a ideia de que a posse de bens de consumo, de objetos materiais (no caso do material analisado os presentes de Natal) são um caminho rápido e seguro para a felicidade. $\mathrm{O}$ exercício de análise dos materiais - os especiais de Natal da Turma da Mônica, veiculados em canal aberto de televisão, na véspera da Natal, no ano de 2002 e entre os anos de 2009 e 2012 - levou-nos a problematizar a constituição de um tipo de infância orientada para o consumo e para a prática de boas ações que se vinculam a possibilidades de recompensa na forma de presentes natalinos, como meio para garantir a felicidade.

A proliferação da educação através de múltiplos espaços sociais, diluída numa "sociedade educativa" (NOGUERA-RAMIREZ, 2011), traz consigo a intensificação de estratégias de condução das condutas infantis, sustentadas pelas narrativas de uma infância desejada e pela crença de que as crianças devem ser educadas, cuidadas, 
ordenadas para um determinado tipo de sociedade, o que leva diferentes instâncias sociais (entre elas a mídia televisiva) a dedicar esforços, para fazer desses pequenos 'futuros homens de proveito', ou 'adaptados à sociedade' ou ainda 'bem colocados na ordem das coisas do mundo' num processo que deve começar logo, de modo a fazer com que desde cedo as crianças sejam iniciadas, conduzidas à lógica da felicidade pelo consumo, pelo objeto material como recompensa pelas condutas corretas.

Esta sociedade que educa (e educar é conduzir), e o faz nos diferentes espaços sociais, mobiliza técnicas de condução orientadas à produção de indivíduos regulados por seus próprios interesses, constituídos no marco de uma "nova cidadania" (TASCHNER, 2010) que, com certa frequência, orienta decisões e escolhas segundo a mesma lógica que preside as escolhas de consumo. Nesse registro, o sujeito/cidadão age como se estivesse adquirindo produtos (que não necessariamente sejam materiais, mas simbólicos, culturais), o que possibilita a compreensão da cidadania, tomada como pertencimento a uma determinada comunidade (a comunidade dos que merecem presentes de Natal, dos que conduzem as suas condutas de modo adequado, pois doam os brinquedos "que não usam mais"), e como reconhecimento da humanidade de um indivíduo e de sua aceitação, não apenas como membro, mas como um par, um igual, um ser visível, digno de respeito (TASCHNER, 2010).

O ingresso à comunidade dos "que fazem o bem e são recompensados" pode ser visto no recorte do diálogo que compõe o especial Véspera de Natal (SOUSA, 2012), em que, mobilizando-se para a boa ação de doar brinquedos às crianças que não ganham presentes no Natal - e sequer se questiona a razão, o que pode indicar o não merecimento -, Cascão diz ao Cebolinha: "Não careca! São os brinquedos que não usamos" e Mônica reforça "Vamos dar só os brinquedos que não usamos mais". No ano anterior, no especial Linda noite de Natal (SOUSA, 2010), a ênfase na doação de brinquedos usados já aparecia com força nos diálogos. Neste episódio, Cebolinha lembra que "nem todas as crianças ganham presentes de Natal". Tal constatação é imediatamente seguida da sugestão: "Hei! A gente podia pegar algum brinquedo que a gente não usa mais e que estão em bom estado e doar para elas!”. É interessante notar que a doação é tão somente daquilo que os personagens não usam mais, daquilo que podem, portanto, descartar. O enredo da história apela para a prática de uma boa ação, o que é valorizado na sociedade em que vivemos e frequentemente espetacularizado. Cascão então diz: "e vai ser por uma boa causa". Assim, entendendo que as boas causas, as boas ações são recompensadas (e por isso devem ser feitas), Cebolinha esfrega as próprias mãos como quem percebe uma vantagem, um ganho e diz: "é... para ganhar brinquedos novos!", o que é acompanhado por um sorriso malicioso.

O olhar que direcionamos à superfície de análise nos possibilitou colocar em suspenso algumas verdades, entre elas a de que o bem, o presente, é uma espécie de remédio, quando não de elixir, para os padecimentos da realidade social. O vídeo mostra cenas em que a Turma da Mônica (muito conhecida pelas crianças) carrega sacos de presentes nas costas, andam enfileirados e distribuem presentes às crianças que estão em situação de vulnerabilidade, abandono, que se encontram sozinhas e na 
rua, na véspera de Natal, tristes e encolhidas nas calçadas da cidade. Ao receberem os presentes, imediatamente sorriem. As imagens centralizam os sorrisos dessas crianças que antes dos presentes estavam tristes. Ao encerrarem a distribuição dos presentes, a tela fica cheia de crianças sorridentes e com brinquedos nas mãos.

O consumo é incentivado pela sedução, pela possibilidade de ganhar objetos que criam e satisfazem o desejo e supõe a manipulação de objetos que são vistos como signos. Isso significa que os objetos são independentes de seus significados e ganham expressão na medida em que confundem a realidade, para suprir a fantasia da acumulação. No especial veiculado em 2012, intitulado Véspera de Natal (SOUSA, 2012), pinguins (tratados no vídeo como ajudantes do Papai Noel) aparecem cantando, enquanto entregam presentes: "Cantem, cantem, cantem até aprender de cor. Um é pouco, dois é bom, três é melhor" (fazendo referência à quantidade de presentes). Já no especial As doze badaladas dos sinos de Natal (SOUSA, 2011), enquanto Cebolinha canta descrevendo o que considera legal no Natal (e em sua narrativa estão incluídos os presentes e o clima de paz e harmonia provocado pelo 'espírito natalino'), ao fundo aparecem imagens de caixas de presentes, todas elas padronizadas, com o mesmo formato, laços enormes e variação apenas na cor. $\mathrm{Na}$ sequência, ainda com a música ao fundo, Papai Noel surge voando em um trenó cheio de presentes. Só então vemos cenas com demonstrações de afeto entre familiares, que se abraçam e se beijam.

As relações interpessoais também vêm passando, cada vez mais, pela perspectiva da materialização. Ou seja, através de objetos, os homens vêm procurando atingir a estabilidade emocional, a autoafirmação, o reconhecimento de si e o reconhecimento pelos outros. Esta busca pela materialidade, pelo objeto, pode ser vista no material analisado. Em uma das cenas do especial As doze badaladas dos sinos de Natal (SOUSA, 2011), Cebolinha empolga-se para abrir a porta de casa ao ouvir a campainha, acreditando ser seu pai que retorna das compras (como informa a mãe). Frustra-se ao se deparar com amigos da turma (Mônica, Cascão e Magali), que chegam um a um. Neste mesmo vídeo e na sequência da cena as falas do Cebolinha são direcionadas à valorização do Natal como um tempo de paz, amor e harmonia. Sua ação, no entanto, é de espera pelos presentes que chegariam pelas mãos do pai, o que torna o pai (e não os amigos) esperado.

No especial Feliz Natal para todos (SOUSA, 2009), o personagem Cebolinha reforça essa compreensão de que o outro adquire valor à medida que permite ou facilita o alcance da coisa desejada, da coisa a ser possuída, o que promove a felicidade. Ao relatar sobre o Natal, Cebolinha diz:

Natal? Deixa eu ver... É dia de ganhar presente, né!? Quer dizer, é dia de esperar presente, mas eu acho que não devia ser desse jeito. Lembro uma vez que eu queria ganhar um patins, mas ganhei uma bola... Fiquei triste e o papai ficou mais ainda. Naquele Natal, ele não tinha tanto dinheiro para comprar assim um patins né. Mas eu não sabia. Senão, eu não tinha feito aquela cara (SOUSA, 2009). 
$\mathrm{O}$ uso de personagens conhecidos pelas crianças, como forma de orientar as condutas infantis, assume papel importante num tempo em que a televisão acompanha as crianças cotidianamente. $\mathrm{O}$ estímulo a um determinado tipo de ações, consideradas positivas, que merecem ser premiadas, objetiva as relações da criança com os outros e com o mundo a sua volta. A centralidade na recompensa imprime nos infantes uma necessidade de retribuição material constante e promove o consumo. Vemos, no especial Natal glacial (SOUSA, 2002), a imagem da Mônica acompanhada de sua amiga Magali, sentada à mesa escrevendo uma carta ao Papai Noel. Mônica lê a carta para Magali "Querido papai Noel, este ano eu fui uma boa menina, por isso eu gostaria de ganhar um urso de pelúcia beeeeem grande!”. Nesse registro, entendemos que o consumo "marca indelevelmente tudo que fazemos e organiza nossa existência. É assim que consumimos também emoções, ideias, modos de ver a vida, de portar-nos, falar e pensar. É assim que além de consumir também nos transformamos em mercadorias e somos consumidos" (ANDRADE; COSTA, 2010, p. 234).

Os vídeos operam como instrumentos de condução que levam a criança a trabalhar sobre si mesma, a assumir uma condução que possa ser considerada adequada, esperada, desejada por ela e pela sociedade, sem se impor como uma obediência cega, mas obtendo uma "obediência reflexiva, aceita como correta" (DUSSEL; CARUSO, 2003, p. 42) tarefa que encontra na mídia um articulador fundamental. Percebemos o acento nesse tipo de obediência, nos especiais de Natal, pela centralidade nos seguintes aspectos: a) na necessidade de controlar os impulsos (Mônica) "Hoje não Magali. Eu estou me controlando. [...] Sua boba! Não sabe que dia é hoje? É véspera de Natal Magali!" (SOUSA, 2012); b) comportar-se de acordo com determinados códigos (Mônica) "E a mamãe falou que o Papai Noel não dá presente para crianças briguentas e mal criadas" (Ibidem) e; c) refletir sobre causas e consequências de seus atos (Sr. Pinguim, ajudante do Papai Noel) "Se vocês não praticarem boas açôes verdadeiras até o final do dia, não tem mais presente de Natal. Entenderam? Nem amanhã e nem nunca mais" (Ibidem). Estes elementos parecem constituir um tipo de criança capaz de refletir sobre seus atos pela condução de um adulto, próximo a ela, que lhes indica a necessidade de seguir um padrão de conduta para ter acesso à recompensa, traduzida nos presentes de Natal.

Desse modo, o material refere à condução das condutas das crianças na direção da autorregulação e prevê o castigo, a punição das condutas inadequadas. Articulado aos preceitos da educação religiosa que deu sustentação à boa parte das tradições educativas que orientam a condução das condutas infantis dentro ou fora dos espaços escolares (a exemplo da mídia televisiva), o castigo deve ser orientado à alma, àquilo que Dussel e Caruso (2003) denominam boa ou má consciência. Todos estão sob o controle uns dos outros, sob os olhares uns dos outros de modo a formar uma "cadeia de vigilância na qual os elos permanecem unidos em função do controle que uns exercem sobre os outros" (Ibidem, p. 90) articulada por relações de poder sustentadas na capacidade de olhar e julgar. Os vídeos apresentam imagens que remetem à vigilância, ao olhar do outro sobre o comportamento das crianças, à presença do olhar sobre todos, de uma presença ausente que tudo vê e à qual devemos obediência. No especial Véspera de Natal (2012), a vigilância permanente aparece com mais força, nos diálogos que explicitam o 
olhar e o julgar, a exemplo de (Magali) "Espere um pouco S. Pinguim. Como é que você ficou sabendo disso tudo?", para o que a resposta é (Sr. Pinguim, ajudante do Papai Noel) “Ora, ora. É que temos câmeras escondidas em todos os lugares". A câmera que tudo vê, observa as condutas infantis e determina o recebimento (ou não) de presentes natalinos. Um tipo de coação é exercido por meio dessa lógica, levando as crianças a se conduzirem a partir de um repertório de condutas autorizadas e incentivadas.

A aprendizagem das condutas se dá mediante os resultados dos esforços e interesses das crianças, assim, tanto o sucesso quanto o fracasso são vistos como decorrentes de seu empenho. Esforços e sucessos precisam ser premiados e os fracassos e desinteresses, punidos. Punição e recompensa, no caso do material em análise, que se manifestam na forma do recebimento, por merecimento, de presentes de Natal, ou seu contrário: a punição de não receber presentes. Assim, o material refere traços do que NogueraRamirez (2011, p. 124) caracteriza como pedagogia cristã uma vez que aproxima disciplina e autocontrole decorrentes de uma ação educativa, pautada na "condição de que a criança aprenda o domínio de si” e deste modo, num processo cujos resultados apontam para a "conformação de um sujeito capaz de se preocupar com sua própria conduta, de exercer uma autocoação, de se autogovernar” (Ibidem, p. 125).

A felicidade é representada nos vídeos como um estado, um estar feliz pela prática de uma virtude, a de adotar boas condutas como "doar brinquedos que não usamos mais", não brigar, exercer o autocontrole, escrever (Cebolinha) "cartinha ao Papai Noel relatando o quanto fui bonzinho, contando tudinho". Desse modo, percebemos o empreendimento de um tipo de governamento de nós mesmos pela razão, o exercício de uma liberdade regulada pelo "acondicionamento do meio", como refere Noguera-Ramirez (2011), pelo uso do desenho animado (de forte apelo no universo infantil) como modo de educar menos para educar mais, de conduzir menos para conduzir mais, para ensinar uma forma de regulação interior.

\section{Por fim...}

Ao final dos caminhos percorridos nesta pesquisa importa sublinhar alguns elementos que nos parecem pertinentes. Olhamos para um conjunto de materiais direcionados às crianças, para entender como as relações de consumo se estabelecem e se legitimam no universo infantil, a partir de um tipo específico de condução das condutas. Entendemos que a dicotomia entre o bem e o mal delimita contornos aceitáveis para as condutas infantis, quando as boas ações são estimuladas por meio de recompensas materiais e, ao fim e ao cabo, determinam as relações que as crianças estabelecem com os objetos. As interações com o mundo e com os seres que o habitam passam por um processo de objetivação, pelo qual se acumulam pontos que são saldados pelo presente natalino. Para garanti-lo, as crianças empreendem um tipo de autocontrole, operacionalizado pela vigilância constante, de si sobre si mesmas, de umas sobre as outras e de uma força permanente que tudo vê e tudo sabe. 
A instituição de estratégias de regramento da infância, pelo tensionamento constante de suas práticas, permite o exercício de um tipo de controle sobre a vida, uma biopolitica que encontra na televisão um meio para exercer-se e, pela lógica de mercado, passa a forjar crianças consumidoras, no cruzamento entre o consumo de objetos, sobretudo materiais, e a sensação, mesmo que passageira, de felicidade. Nada mais atual, num mundo efêmero como o nosso, que produzir, desde a infância, as condições para movimentar a roda da economia forjando nos indivíduos o desejo pelo consumo.

\section{REFERÊNCIAS}

ANDRADE, Paula Deporte de; COSTA, Marisa Vorraber. Usando crianças para vender: infância e consumo na publicidade de revistas. Reflexão e Ação / UNISC, Santa Cruz do Sul, v.18, n2, jul./dez. 2010, p.230-248. Disponível em: <https://online.unisc.br/seer/index.php/ reflex/article/view/1551>. Acesso em: 26 maio 2015.

ARENDT, Hanna. Entre o passado e o futuro. São Paulo: Editora Perspectiva, 1979.

BAUMAN, Zigmunt. Vida para consumo: a transformação das pessoas em mercadorias. Rio de Janeiro: Jorge Zahar Editora, 2008.

CAMPOS, Cristina Caldas Guimarães de; SOUZA, Solange Jobim e. Mídia, cultura do consumo e constituição da subjetividade na infância. Psicologia, Ciência e Profissão/ CFP. Vol. 23, n.1, 2003, p.12-21. Disponível em: <http://pepsic.bvsalud.org/pdf/pcp/v23n1/ v23n1a03.pdf >. Acesso em: 26 maio 2015.

DUSSEL, Inês; CARUSO, Marcelo. A invenção da sala de aula. Uma genealogia das formas de ensinar. São Paulo: Moderna, 2003.

FOUCAULT, Michel. Em defesa da sociedade: Curso do Collège de France, 1975-1976. São Paulo: Editora WMF Martins Fontes, 2010.

LOPES, Maura Corcini. Políticas de Inclusão e Governamentalidade. In: Educação \& Realidade. V.34, n.2. Porto Alegre: Universidade Federal do Rio Grande do Sul, Faculdade de Educação, maio/ago. 2009.

NOGUERA-RAMIREZ, Carlos Ernesto. Pedagogia e governamentalidade. Ou da modernidade como uma sociedade educativa. Belo Horizonte: Autêntica, 2011.

PAGNI, Pedro Angelo. Um ensaio sobre a experiência, a infância do pensamento e a ética do cuidado: pensar a diferença e a alteridade na práxis educativa. In: KOHAN, Walter Omar.

Devir criança da filosofia: infância da educação. Belo Horizonte: Autêntica, 2010.

SENNETT, Richard. Juntos: os rituais, os prazeres e as políticas de cooperação. Rio de Janeiro: Editora Record, 2012.

SOUSA, Mauricio Araújo de. Turma da Mônica em: As doze badaladas dos sinos de Natal. 2011 (25 min 32 s). Disponível em: <https://www.youtube.com/watch?v=rzDQZcwfNiw>. Acesso em: 10 abr. 2015. 
SOUSA, Mauricio Araújo de. Turma da Mônica em: Feliz Natal para todos. 2009 (25 min 41s). Disponível em: <https://www.youtube.com/watch?v=RdmsiOTjj9E >. Acesso em: 10 abr. 2015.

SOUSA, Mauricio Araújo de. Turma da Mônica em: Linda noite de Natal. 2010 (26 min 03 s). Disponível em: <https://www.youtube.com/watch?v=0O2aVH5Z0Ps>. Acesso em: 10 abr. 2015.

SOUSA, Mauricio Araújo de. Turma da Mônica em: Um Natal glacial. 2002 (7 min 16 s). Disponível em: <https://www.youtube.com/watch?v=-dj77tui45s >. Acesso em: 10 abr. 2015.

SOUSA, Mauricio Araújo de. Turma da Mônica em: Véspera de Natal. 2012 (25 min 18 s). Disponível em: <https://www.youtube.com/watch?v=4FiIeBNa22A >. Acesso em: 10 abr. 2015.

TASCHNER, Gisela. Cultura do consumo, cidadania e movimentos sociais. Revista

Ciências Sociais Unisinos, São Leopoldo, vol. 46, n.1, jan/abr 2010, p. 47-52. Disponível em: $<$ http://revistas.unisinos.br/index.php/ciencias_sociais/article/view/170/40>. Acesso em: 27 maio 2015. 